\title{
NOTES
}

\section{Dielectric Properties of Polypropylene/ Polycarbonate Polyblends}

\author{
P. K. C. Pillai, G. K. Narula, and A. K. Tripathi \\ Department of Physics, Indian Institute of Technology, \\ New Delhi-110016, India
}

(Received February 2, 1984)

\begin{abstract}
KEY WORDS Dielectric Properties / Polypropylene and Polycarbonate Polyblends / AC Measurements /
\end{abstract}

AC measurements give an important tool in the study of polarization and dielectric relaxation in polymer dielectrics. Most of the interesting properties of polymers are due to the molecular motions which are very complex. In a polymeric system, the molecular relaxations correspond to various transitions of the polymer. The investigation of dielectric dispersion of polymers has been popular in recent years and considerable literature now exists. ${ }^{1-3}$ The dielectric relaxation depends on the total chain length, frequency, temperature, pressure $e^{4-6}$ and in some cases is a function of plasticiser concentration, ${ }^{7}$ curing agent, ${ }^{8}$ complex formation and co-polymerization. ${ }^{9}$

The dielectric measurements made on polypropylene (PP)/Polycarbonate (PC) polyblends are reported in this paper in the frequency range 1 to $100 \mathrm{kHz}$ and temperature range $50-170^{\circ} \mathrm{C}$. The dielectric constant $\varepsilon^{\prime}$ and dielectric loss $\varepsilon^{\prime \prime}$ were measured as functions of frequency and temperature.

The results have been explained on the basis of induced dipole formation.

\section{EXPERIMENTAL DETAILS}

$\mathrm{PP}$ and $\mathrm{PC}$ in the form of transparent granules were obtained from Sri Ram Institute of Industrial Research, Delhi, India and Bayer, Germany, respectively. The blends were made by taking the two polymers in different weight proportions (10 to 90) in a melt extruder and later the films were made by compression moulding. The different blend ratios used in present studies include.

(10/90), (40/60), (50/50), (60/40), and (90/10) weight proportions of $\mathrm{PC}$ and $\mathrm{PP}$ and are designated as $\mathrm{PP}_{1}, \mathrm{PP}_{4}, \mathrm{PP}_{5}, \mathrm{PP}_{6}$, and $\mathrm{PP}_{9}$, respectively.

A sample of $(2 \times 2) \mathrm{cm}^{2}$ was cut from each film for AC dielectric measurements. The aluminium electrodes were vacuum deposited on both sides of the film on an area of $(1.4 \times 1.5) \mathrm{cm}^{2}$. A 1615 A type General Radio bridge was used for measuring the dielectric Permittivity and dielectric loss in the polyblend systems. Measurements were made in the frequency range 1 to $100 \mathrm{kHz}$ and in the temperature range from room temperature to $170^{\circ} \mathrm{C}$.

\section{RESULTS AND DISCUSSION}

The effect of temperature and frequency variation on $\varepsilon^{\prime}$ and $\tan \delta$ of various polyblends is shown in Figures $1-3 \varepsilon^{\prime}$ has been found to be independent of frequency of the 
P. K. C. Pillai, G. K. Narula, and A. K. Tripathi

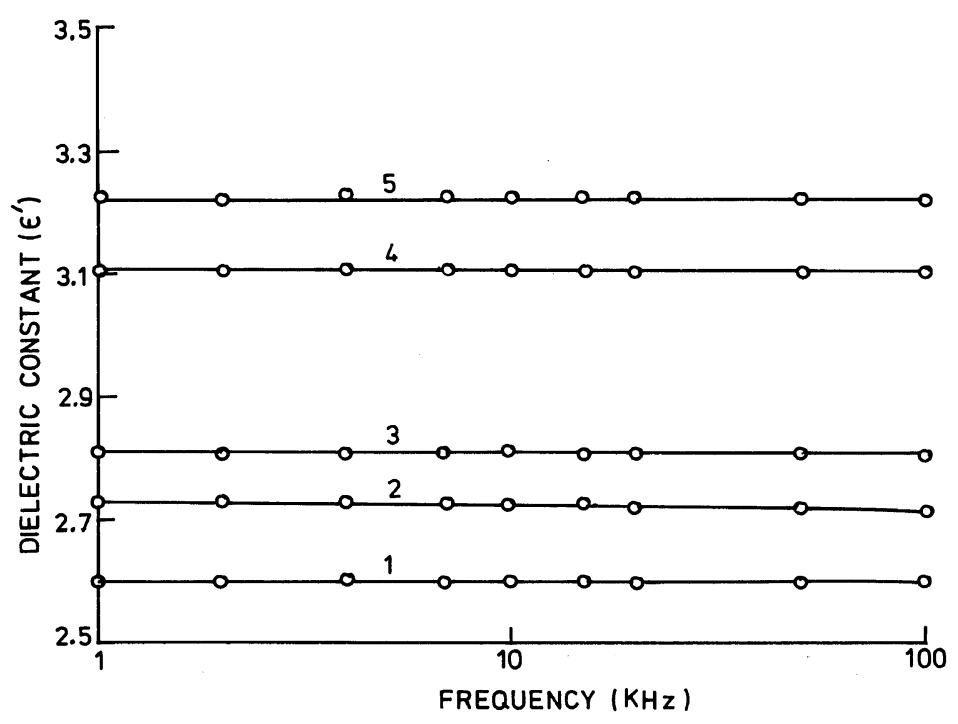

Figure 1. Permittivity as a function of frequency: $1, \mathrm{PP}_{1} ; 2, \mathrm{PP}_{4} ; 3, \mathrm{PP}_{5} ; 4, \mathrm{PP}_{6} ; 5, \mathrm{PP}_{9}$.

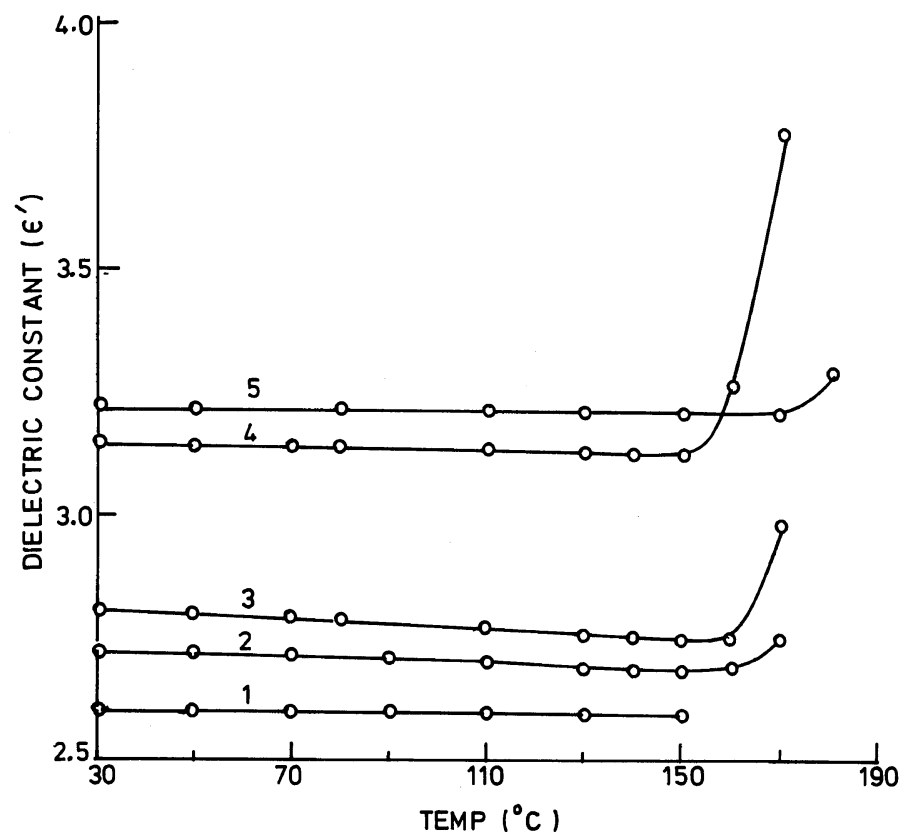

Figure 2. Permittivity as a function of temperature: $1, \mathrm{PP}_{1} ; 2, \mathrm{PP}_{4} ; 3, \mathrm{PP}_{5} ; 4, \mathrm{PP}_{6} ; 5, \mathrm{PP}_{9}$.

applied field for all the polyblends (Figure 1). This is in accordance with the dielectric response of non-polar dielectrics. ${ }^{10}$ With an increase in temperature $\varepsilon^{\prime}$ remained almost constant or decreased slightly in some polyblends up to $150^{\circ} \mathrm{C}$ and after that increased sharply in all the systems studied (Figure 2). The temperature dependence of $\tan \delta$ at fixed frequency $(20 \mathrm{~K})$ is shown in Figure 3 for various polyblends. Here again it is found that $\tan \delta$ 


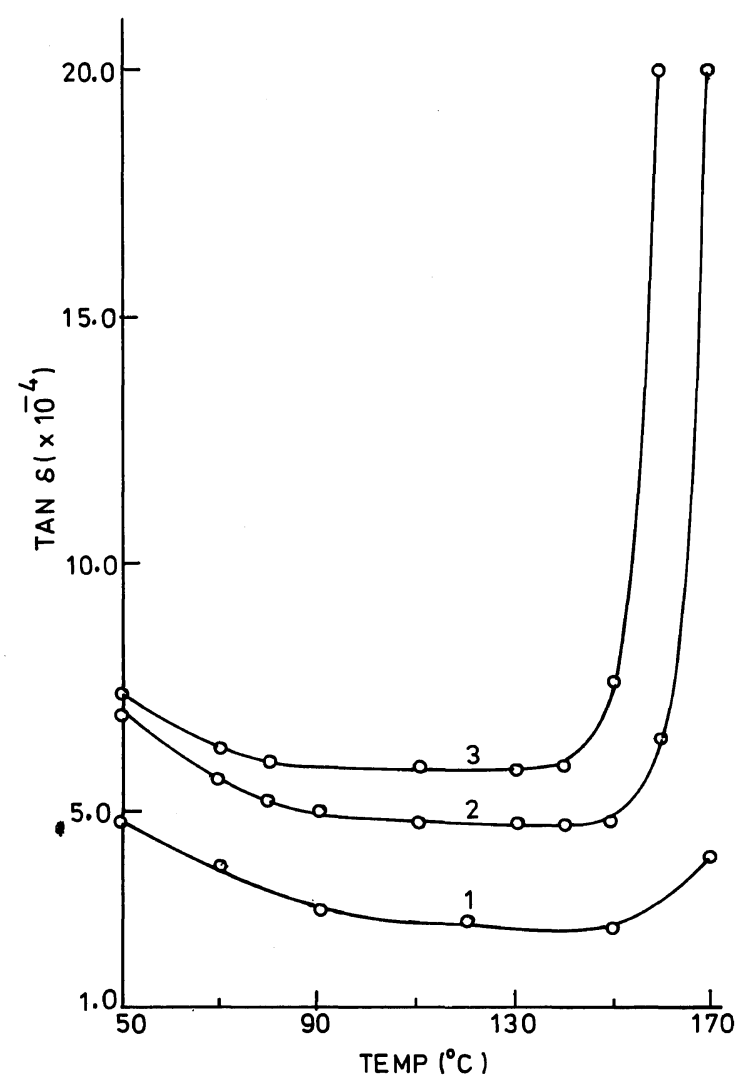

Figure 3. Loss tangent as a function of temperature: $1, \mathrm{PP}_{4} ; 2, \mathrm{PP}_{5} ; 3, \mathrm{PP}_{6}$.

decreases slightly with temperature up to $\sim 150^{\circ} \mathrm{C}$ and then shows a sudden increase with further rise in temperature. However, no dependence of $\tan \delta$ was found on the frequency of the AC field.

The polyblends under study are made up of one polar (PC) and one non-polar (PP) component. They are heterogeneous mixtures, and thus contain a large number of trapping sites. As is clear from Figures 1 and 2 the dipolar contribution of PC towards the total polarization of polyblends is not much because we are concerned with the non-polar characteristics. In the case of polar dielectrics, ${ }^{10} \varepsilon^{\prime}$ decreases with an increase in frequency and also $\varepsilon^{\prime}$ increases with an increase in temperature owing to the increase in polarization in these materials. But in the present polyblends, $\varepsilon^{\prime}$ remained almost constant with frequency and also with temperature (or decreased slightly) up to $150^{\circ} \mathrm{C}$. Since the applied field in the $\mathrm{AC}$ measurements is very weak as compared to the field value in TSC or DC conduction studies $\left(\sim 20 \mathrm{kV} \mathrm{cm}^{-1}\right)$, the injected charge density from the electrodes into the polymer is almost negligible in this case and only the thermally generated carriers (bulk generated) dominate in the present experiments. On application of an AC field at room temperature or $\sim 50^{\circ} \mathrm{C}$, trapping of charge carriers takes place which leads to induced dipole formation. As the temperature of the system increases, the mobility of carriers increases slightly and also the trapping will decrease marginally, leading to a lowering of polarization. Owing to this $\varepsilon^{\prime}$ decreases slightly 
with temperature initially. At around $150^{\circ} \mathrm{C}$ the molecular motion increases to such an extent that the induced dipoles which were formed start orienting under the applied field. This gives rise to sudden increases of $\varepsilon^{\prime}$ and $\tan \delta$ with further increase of temperature.

Our TSC (thermal stimulated current) ${ }^{11}$ and step response measurement ${ }^{12}$ studies on these polyblends have also suggested charge carrier trapping leading to induced dipole formation.

\section{CONCLUSION}

The AC measurements in polyblends of PC and PP show that the dielectric relaxation in these systems is due to induced dipoles formed as a result of trapping of charge carriers in deeper traps and their orientation at higher temperatures.

\section{REFERENCES}

1. F. E. Karasz, Ed., "Dielectric Properties of Polymers," Plenum Press, New York, N. Y., 1972.

2. N. G. McCrum, B. E. Read, and G. Williams, "Anelastic and Dielectric Effects in Polymeric Solids," John Wiley, New York, N. Y., 1967.

3. P. Hedvig, "Dielectric Spectroscopy of Polymers," Ademhilger, Bristol, 1977.

4. H. Sasabe and S. Saito, J. Polym. Sci., 6, 1401 (1968).

5. G. Williams, Trans. Faraday Soc., 62, 2091 (1966).

6. G. Williams and D. A. Edwards, Trans. Faraday Soc., 62, 1329 (1966).

7. R. M. Fuoss, J. Am. Chem. Soc., 63, 378 (1941).

8. J. Gowri Krishna, O. S. Josyulu, J. Sobhandri, and R. S. Subrahmanian, J. Phys. D, Appl. Phys., 15, 2315 (1982).

9. P. K. C. Pillai and Rashmi, Int. J. Polym. Mater., 8, 255 (1980).

10. B. Tareev, "Physics of Dielectric Materials," Mir Publishers, Moscow, 1979.

11. P. K. C. Pillai, G. K. Narula, A. K. Tripathi, and R. G. Mendiratta, Phys. Rev., B, 272508 (1983).

12. P. K. C. Pillai, G. K. Narula, A. K. Tripathi, and R. G. Mendiratta, Phys. Status Solidi (a), 77, 693 (1983). 